\title{
Arousal Increases Self-Disclosure ${ }^{* \dagger}$
}

* This research was supported by a faculty of business and economics research grant FRG2016 at the University of Melbourne, Victoria, Australia.

$\dagger$ We report all measures, manipulations, and exclusions in these studies 


\begin{abstract}
This research tests the hypothesis that arousal increases self-disclosure. We find that affective arousal increases the amount (study 1) and the severity (study 2) of self-disclosure, and that self-disclosure is also increased by physiological arousal (study 3). We further explore the moderating effect of thought frequency on the arousal-disclosure relationship, finding that oftenthought-about thoughts are more likely to be disclosed than less thought-about thoughts. This research has practical importance in terms of understanding when and why people self-disclose personal information, and enriches our understanding of the theoretical relationship between arousal and information sharing.
\end{abstract}

\title{
Keywords
}

Self-disclosure, dominant response, arousal 


\section{Introduction}

Disclosing personal information to others influences impressions that may lead to positive or negative outcomes. A woman might disclose in a job interview that she never wants to have children, perhaps viewed by the prospective employer as positive. But another interviewee may let it slip that they hate Mondays, leaving a negative impression. Given the effect that disclosing personal information often has on others' judgments, people regulate the types of information they reveal in social encounters (Cameron, 2009). In general, people make efforts to conceal intimate thoughts, feelings, and other personal information to less well-known associates for fear of being judged, though strategically disclose more personal information over time to build rapport, signal trust, and bond (Omarzu, 2000; Sprecher, Treger, Wondra, Hilaire, $\&$ Wallpe, 2013). Yet despite people's best intentions to regulate the concealment and disclosure of personal information, sometimes people let something slip that they might later regret. Which begs the question; when and why do people self-disclose?

Generally, highly personal information takes some degree of effort to suppress in social situations. Some personal information in social situations tends to be often thought about. For example, research on secrets suggests that information that requires effort to suppress, including some personal information, is prone to 'mind wandering' whereby an individual will often think about the information (Slepian, Chun, \& Mason, 2017). Efforts to suppress information increases mind wandering, making it more accessible and paradoxically more difficult to suppress (Lane \& Wegner, 1995). According to the social facilitation literature, habitual behaviors and thoughts may become a dominant response, which is more likely performed when an individual is aroused (Bond \& Titus, 1983; Guerin, 2009). For example, well-learned or rehearsed information is more likely to be recalled when aroused than new or difficult information (Zajonc \& Sales, 1966). 
Consistent with the idea that habitual thoughts and behaviors are more likely to surface when aroused, we explore the idea that people might be more likely to disclose highly personal information when they are aroused.

Most work in this area has focused on the subjective benefits or negative consequences of self-disclosure, gender differences, and reciprocity (for reviews see: Dindia, 2001; Ruppel et al., 2016), but little has been done to understand the factors that influence efforts to conceal or disclose personal information. We examine the hypothesis that affective and physiological arousal increases tendencies to self-disclose personal information.

\section{Self-Disclosure}

Self-disclosure is when an individual reveals intimate thoughts, feelings, and private details about their lives to others (Dindia, Fitzpatrick, \& Kenny, 1997). Self-disclosure enhances bonding when building and maintaining relationships, and may be beneficial for psychological health (Cameron, 2009; Pennebaker, 1995). In dyadic encounters, people disclose personal information in concordance with how much personal information is disclosed to them from the other (Rubin, 1975). Sharing personal information signals trust, and people estimate how they are perceived by noting the frequency and intensity of reciprocated disclosure (Sprecher, et al., 2013).

Our study is focused on self-disclosure to strangers, such as when an individual describes themselves in public settings, or to someone they have only just met. Although there are benefits self-disclosing to others, there are also risks that include rejection, reduction of autonomy, and the possibility of embarrassment (Cline, 1989). In most situations, people do not usually share 
deeply personal information to someone they have just met, and will tend to strategically moderate the level of personal disclosure with the aim of controlling others' perceptions and judgements (Omarzu, 2000; Place, Todd, Penke, \& Asendorpf, 2009).

Generally people will say things in social situations that puts them in a good light, but they also make efforts to conceal information that may seem circumstantially inappropriate (Lane \& Wegner, 1995). The types of information people make efforts to conceal in public include overly personal facts and information that may reflect poorly on character (Altman \& Taylor, 1973; Tolstedt \& Stokes, 1984). Ironically, actively suppressing thoughts makes those same thoughts more accessible, and the more often one tries to suppress the thoughts, the more likely the thought comes to mind, creating a cycle of rumination and intentional suppression (Gold \& Wegner, 1995). This process is demonstrated in Wegner's (1987) well-known white bear study, in which participants told not to think about a bear demonstrated significantly more bear thoughts than participants told to think about the bear. Paradoxically, efforts to suppress certain thoughts winds up enhancing further thoughts on the matter.

People are averse to breaking the status quo and are thus inclined to conform to social norms that when broken leads to regret. In social situations, people hold concerns over others' evaluations of themselves, and will try to avoid the embarrassment associated with making an unwanted impression (Bell, 1982). People care about making a good impression, either driven by a desire to match expectations of the ideal self, or an audience's expectations of personal image (Baumeister \& Hutton, 1987). Driving impression management is fear of isolation and ostracism, which motivates people to share information that puts them in a good light, and to not share information that could be perceived as inappropriate (Cacioppo, Hawkley, Norman, \& Berntson, 2011; Leary, 2010). Evidence suggests that concealing and disclosing personal information 
requires some degree of conscious effort, since disclosing certain information at an inopportune time may result in negative consequences (Omarzu, 2000). The effort involved with moderating the disclosure and concealment of personal information is similar to the effort involved with concealing secrets (Lane \& Wegner, 1995; Slepian, Camp, \& Masicampo, 2015).

Efforts to suppress thoughts in social situations may increase how often the thought is thought about, but the mind may also 'wander' to information one takes efforts to conceal at irrelevant non-social occasions, such as waiting in traffic or sitting in class (Slepian, et al., 2015). Slepian (2017, experiment 2) for example found that mind wandering to secrets in irrelevant settings occurred more often than efforts to conceal the information during social interactions. In a similar vein, we suggest that it is not just the notion of keeping information concealed that leads to habituation, but rather the psychological consequences of having the information in the first place.

\section{Arousal and Self Disclosure}

Why might arousal increase self-disclosure? The social facilitation literature suggests that habitual behaviors are more likely to be performed when aroused, and rehearsed information is more readily accessible when aroused (Zajonc, 1965; Zajonc \& Sales, 1966). Since highly personal information is familiar and often thought about, requires effortful concealment (Omarzu, 2000), and the mind frequently 'wanders' to information that requires effort to conceal (Slepian, et al., 2017), then it seems that highly personal information might also be more accessible and therefore disclosed when aroused.

A response becomes dominant with rehearsal and habituation, and when a behavior is 
well-learned or habitual, then it is a dominant response (Zajonc, 1965). The psychology literature has demonstrated that dominant responses are more likely to be produced under conditions of high arousal both because arousal lessens cognitive control, and because it strengthens the activation of habitual well-rehearsed responses. [For a discussion of these processes, see Conrey et al. (2005)]. People perform better on familiar, well-learned tasks and decisions under high arousal (Hull, 1943; Zajonc, 1965), but worse on tasks that are new and difficult (Yu \& Wu, 2015; Zajonc \& Sales, 1966). Particularly relevant to the present investigation is early research done by Zajonc and Sales (1966) that suggests that arousal facilitates the recall of rehearsed (often thought about) information. They found that aroused participants who rehearsed nonsensical words later identified more of the non-sensical words than non-aroused participants.

Arousal also appears to lower inhibitions with regards to the types of information disclosed when formulating impressions. For example, Lambert et al. (2003) found that people were more likely to rely on stereotypical beliefs in (anticipated) public than private settings. They hypothesized that this counterintuitive result might occur because stereotypical thoughts are a dominant response that is 'energized' by the actuality or expectation of communicating in public.

\section{Overview of studies}

In sum, we suggest that highly personal information is more likely to be disclosed when aroused. We test our hypothesis in three studies. In study 1 we conduct a preliminary test on the idea that arousal increases tendencies to disclose personal information, and explore the different types of personal information disclosed. In study 2 we test the severity of personal disclosure, examining the idea that people will tend to disclose personal experiences that are regarded as 
being more disgraceful when aroused. We rule out the possibility that arousal might enhance tendencies to self-disclose personal information through motives to self-promote. Finally, in study 3 we test whether our prediction holds for physiological arousal, and conduct a JohnsonNeyman significance region analysis (Johnson \& Neyman, 1936) to understand the extent to which thought frequency affects the relationship between arousal and disclosure.

\section{Study 1: Dating Profile}

The aim of study 1 was to provide an initial test of our prediction that arousal increases tendencies to share personal information. We asked participants to share information about themselves for a dating profile, predicting that arousal would increase the intensity of personal information disclosed.

\section{1 Method}

5.1.1. Participants and design. Eighty-six undergraduate students participated in the study in return for a $\$ 20$ gift card. A sensitivity analysis conducted with $\mathrm{G} *$ Power (Faul, Erdfelder, Lang, \& Buchner, 2007) suggested that the sample size was sufficient to detect small-medium sized effects $(f=0.31$ assuming $\alpha=0.05$ and power $=0.80)$. Forty-three percent were female, 92\% fell into an 18-25 year old age bracket, and the remaining $8 \%$ fell into a 26-34 age bracket. Participants were randomly split into two groups: a control group and treatment group where arousal was evoked in a between-subjects design. No data were excluded from analysis. 


\subsubsection{Procedure. Participants were told they were participating in a study to learn more} about online dating websites. All participants were told to imagine they were setting up a new profile on a popular dating website, and to list three things about themselves they would like to include. The study was conducted in a computer laboratory, and participants recorded their responses directly into survey software on a computer.

Based on the manipulations used by Ben-Zeev et al. (2005), arousal was evoked in the treatment group by explaining that the study was in two parts, and that in the second part they would be required to complete a challenging math test to learn more about their analytical skills. A pretest was conducted to ensure this manipulation would work. Forty-one students were randomly split into two groups, where both groups were given a filler task, and one group was told they would be required to complete a very challenging and difficult standardized test of their ability in math. Arousal was measured on Schimmack and Grob's (2000) semantic differential arousal scale (awake-tense, wakeful-tired, alert-drowsy, tense-relaxed, clutched up-calm, jitteryat rest). A one way ANOVA suggested arousal was significantly higher in the treatment group $(M=3.99, S D=.72,95 \% \mathrm{CI}=[3.67,4.31])$ than control group $(M=3.51, S D=.44,95 \% \mathrm{CI}=$ $[3.30,3.72]) F(1,39)=6.39, p=.016, \eta^{2}=.14$, suggesting the arousal manipulation was successful. Since the purpose of this study was to examine the effects of arousal on personal information disclosure, participants were not required to take the math test, since the expectation of the impending math test was all that was needed to invoke arousal (Ben-Zeev, et al., 2005).

\subsubsection{Dependent variable. Two students (one male and one female) blind to the hypotheses} and who did not participate in the study coded each of the three things each respondent wanted to include on their dating profile as being either fully (2), somewhat (1), or not at all (0) representative of one of six predefined categories of personal information. The categories were 
defined by Okkan et al. (2013), and included fears (FEAR), responses that were highly emotive (EMOT), responses that disclosed an embarrassing experience (EMBRS), responses that were incriminating (INCRIM), responses that were oddly intimate (INT), and responses that were negative but suggested growth (GROW). Initial agreement between the judges on coding the responses was $76 \%$, and disagreements between the judges were resolved through discussion. The dependent variable 'self-disclosure' was constructed by summing the judges scores on each category.

\subsubsection{Other measures}

To identify potential moderating factors, several exploratory measures were included in the questionnaire including extraversion (Sato, 2005), impulsiveness (Spinella, 2007), and selfmonitoring (Lennox \& Wolfe, 1984).

\section{2 Results and Discussion}

\subsubsection{Manipulation check As a check for whether the impending math test manipulation} worked, participants completed the same arousal scale used in the pre-test $(\alpha=.74)$. A one-way ANOVA suggested the treatment group informed of the impending math test had greater arousal $(M=4.39, S D=1.04,95 \% C I=[4.07,4.71])$ than the control group $(M=3.81, S D=.87,95 \%$ $\left.C I=[3.54,4.09]) F(1,84)=7.75, p=.007, \eta^{2}=.08\right)$, suggesting the manipulation was successful. 


\subsubsection{Arousal affecting sharing A one-way ANOVA found a significant difference}

between the treatment groups and control groups for each variable except for GROW (table 1).

Overall, the analysis found a significant difference between the treatment $(M=5.73, S D=3.15$, $95 \% C I=[4.79,6.68])$ and control groups $(M=1.63, S D=1.39,95 \% C I=[1.19,2.07]) F(1,84)$

$\left.=58.88, p<.001, \eta^{2}=.41\right)$ when all personal variables were combined. A simple linear regression was calculated to predict self-disclosure based on measured arousal. A significant regression equation was found $(F(1,84)=13.83, p<.001)$, with an $R^{2}$ of .14. Self-disclosure increased 1.20 points on the scale assessed by the judges for each point increase on the arousal scale. Taken together, these results support our prediction that aroused participants are more likely to share more personal information.

Table 1: Example items coded for each category of personal information type

\begin{tabular}{|c|c|c|}
\hline $\begin{array}{l}\text { PERSONAL } \\
\text { INFORMATION TYPE }\end{array}$ & EXAMPLE PERSONAL COMMENTS & $\begin{array}{l}\text { ANOVA: FREQUENCY OF } \\
\text { PERSONAL COMMENTS } \\
\text { DISCLOSED BETWEEN } \\
\text { GROUPS }\end{array}$ \\
\hline FEARS & $\begin{array}{l}\text {-I prefer to move slow. My biggest fear is rejection } \\
\text {-I prefer to say inside rather than go out }\end{array}$ & $\begin{array}{l}F(1,84)=11.39, p=.001, \eta^{2} \\
=.12,95 \% \mathrm{CI}=[.080, .315]\end{array}$ \\
\hline EMOT & $\begin{array}{l}\text {-I hate people who are unwilling to change } \\
\text {-Honesty is the best policy- but honesty is my only policy. I hate lies, } \\
\text { and I promise you won't hear any from me }\end{array}$ & $\begin{array}{l}F(1,84)=15.15, p<.001, \eta^{2} \\
=.15,95 \% \mathrm{CI}=[1.191,1.736]\end{array}$ \\
\hline EMBRS & $\begin{array}{l}\text {-I am not comfortable with my body but I have a nice personality and } \\
\text { I am mostly happy } \\
\text {-I'm usually very shy around attractive people, but I'm working on it! }\end{array}$ & $\begin{array}{l}F(1,84)=8.57, p=.004, \eta^{2} \\
=.09,95 \% \mathrm{CI}=[.195, .502]\end{array}$ \\
\hline INCRIM & $\begin{array}{l}\text {-I like to get high } \\
\text {-I smoke weed and hope my future girlfriend partakes too }\end{array}$ & $\begin{array}{l}F(1,84)=4.74, p=.032, \eta^{2} \\
=.05,95 \% \mathrm{CI}=[.012, .198]\end{array}$ \\
\hline INTIMATE & $\begin{array}{l}\text {-But relaxing is awesome, too. I'm also a cozy beach house and } \\
\text { fireplace kind of guy on a cool winter night } \\
\text {-I can't cook- but that's okay, because I would much rather get some } \\
\text { cheap take-out and sit in a park or beach and eat it with you while we } \\
\text { talk... }\end{array}$ & $\begin{array}{l}F(1,84)=62.20, p<.001, \eta^{2} \\
=.43,95 \% \mathrm{CI}=[1.165,1.812]\end{array}$ \\
\hline GROW & $\begin{array}{l}\text {-I'm usually very shy around attractive people, but I'm working on it! } \\
\text {-I have been in a toxic relationship before and I am looking for } \\
\text { someone who is kind }\end{array}$ & $\begin{array}{l}F(1,84)=1.77, p=.19, \eta^{2}=.02 \\
95 \% \mathrm{CI}=[.064, .284]\end{array}$ \\
\hline
\end{tabular}

Example neutral comments: I love to cook, I love history, I am fun. 


\subsubsection{Exploratory measures To test whether any of the exploratory variables including} extraversion, impulsiveness, and self-monitoring affected self-disclosure as a function of arousal, each was included as a moderator in an equation regressing self-disclosure on arousal (PROCESS, model 1, Hayes 2013). The results found no statistically significant interaction for extraversion $b=.04, t(81)=0.19, p=.84,95 \% C I=[-.38, .46])$; impulsiveness $b=.14, t(81)=0.30, p=.74,95 \% C I=[-1.06, .78])$; or self-monitoring $b$ $=.49, t(81)=1.49, p=.14,95 \% C I=[-1.15, .16])$, thus suggesting differences in these traits did not explain the results.

\section{Study 2}

Study 1 provided preliminary evidence in support of our hypothesis that arousal increases the amount of personal information disclosed. In study 2 the objective was to examine the severity of personal self-disclosure when aroused. Specifically, we asked participants to describe a time when they wrote inappropriate, unkind, or rude comments online, predicting that the severity of the experience disclosed by aroused participants would be greater than non-aroused participants. We also asked to participants to indicate the extent to which they would have preferred to keep the disclosed information secret, predicting that arousal affects the disclosure of information that requires some degree of effort to conceal. 


\subsubsection{Participants and design. Data were collected from Mturk (Amazon's Mechanical}

Turk), which is a database of anonymous volunteers who participate in online research studies in return for modest payments. Collecting data from Mturk allowed us to sample from the general public, therefore ensuring our results would be more representative of the U.S. population than sampling from undergraduates (Paolacci, Chandler, \& Ipeirotis, 2010). The quality of data from Mturk has been found to be comparable to data gathered from student undergraduates (Buhrmester, Kwang, \& Gosling, 2011). Additionally, for the purposes of our study, Mturk participants are more diverse and have a wider range of experiences, that has been found to be beneficial in prior research that has elicited secret experiences (Slepian, et al., 2017).

One hundred and sixty participants (46\% female, average age 39) were randomly split into two groups: a control group and treatment group where arousal was evoked in a between-subjects design. A sensitivity analysis conducted with $G^{*}$ Power (Faul, et al., 2007) suggested that a sample size of 128 would be sufficient to detect was sufficient to detect smallmedium sized effects $(f=0.25$ assuming $\alpha=0.05$ and power $=0.80)$, and a sample size of 160 would result in power $=0.88$. No data were excluded from analyses.

\subsubsection{Procedure. The sample was randomly split into treatment and control groups using} computer code embedded into online survey software. Arousal was manipulated by showing participants pictures taken from the International Affective Picture System (Lang, Bradley, \& Cuthbert, 1997). The pictures in the IAPS are categorized into dimensions of affective valence (ranging from pleasant to unpleasant) and arousal (ranging from calm to excited), on 9-point scales for each dimension making it possible to select pictures that vary in the intensity of arousal, while holding valence constant. The images have been successfully used to evoke arousal in a similar manner in previous research (Noseworthy, Muro, \& Murray, 2014). In the 
treatment group participants were shown three images that were highly arousing (IAPS picture IDs 8160 [rock climber] $M_{\text {valence }}=5.07 ; S D_{\text {valence }}=1.97,5950$ [lightening] $M_{\text {valence }}=5.99$; $S D_{\text {valence }}=2.07$, and $1321[$ biking/train $\left.] M_{\text {valence }}=4.85 ; S D_{\text {valence }}=1.85\right)$. In the control group participants were shown three non-arousing pictures (IAPS picture IDs 7004 [spoon] $M_{\text {valence }}=$ 5.04; $S D_{\text {valence }}=.60,7010$ [basket $] M_{\text {valence }}=5.94 ; S D_{\text {valence }}=1.07$, and 7175 [lamp] $M_{\text {valence }}=$ 4.87; $\left.S D_{\text {valence }}=1.00\right)$. After the images were shown, and on a new page, participants were asked to describe a time when they engaged in trolling, or otherwise making inappropriate, unkind, or rude comments online. To adhere to ethics committee guidelines, participants were also instructed not to disclose anything that might be considered illegal, including physical threats to harm, malicious stalking, defamation, and encouraging suicide. Arousal was measured after participants had described their experiences.

\subsubsection{Dependent variable. The dependent variable was severity of disclosure ("Severity").} We recruited two judges (one male and one female student, both blind to the hypotheses) and asked them to rate the severity of personal disclosure ("information one would not normally disclose, would normally keep to themselves, and that in hindsight might cause the person to regret disclosing"; 1 = strongly disagree, 7 = strongly agree). Disagreements between the judges were resolved through discussion (Cohen's Kappa $=.65)$.

\subsubsection{Measures. After describing their experience, all participants completed a set of} questions that included measures of arousal (the scale used in study $1 ; \alpha=.86$ ), and whether they would prefer to keep their experience a secret ("Secret"), since our theory predicts that arousal should increase the likelihood of disclosing information that requires some degree of effort to conceal (I would prefer it if the experience I wrote about was kept a secret; 1 = strongly disagree, 7 = strongly agree). 
To ensure that arousal did not enhance tendencies to impress others and to ensure there were no baseline differences between the groups, we further measured self-presentation and need to belong using Hewitt et al.'s (2003) self-presentation scale (e.g., It would be awful if I made a fool of myself in front of others, I should always keep my problems to myself, It is okay to admit mistakes to others, I try to keep my faults to myself; $1=$ strongly disagree, $7=$ strongly agree; $\alpha$ $=.87$ ), and items adapted from Leary et al.’s (2013) "need to belong” scale (e.g., I want other people to accept me, I have a strong need to belong, My feelings are easily hurt when I feel that others do not accept me, I try hard not to do things that will make other people avoid or reject me; $1=$ strongly disagree, $7=$ strongly agree; $\alpha=.90)$. Finally, after completing these measures participants completed items adapted from Noseworthy et al. (2014) to assess their feelings towards the pictures ("I had pleasant feelings while viewing the pictures", "The pictures made me feel happy", "I was disgusted by the pictures", "The pictures made me feel good", "I was fearful looking at the pictures", "The pictures made me feel bad", "The pictures made me feel angry", "The pictures made me feel joyful", and "The pictures made me feel sad"; 1 = strongly disagree, 7 = strongly agree).

\section{2 Results and Discussion}

A one-way ANOVA found that the treatment group was more aroused $(M=4.27, S D=$ $1.43,95 \% C I=[3.99,4.56])$ than the control group $(M=3.89, S D=1.30,95 \% C I=[3.57,4.22])$ $\left.F(1,158)=2.93, p=.018, \eta^{2}=.018\right)$, suggesting the arousal manipulation was successful. Multivariate analysis of variance found no other significant affective differences between the groups (see table 2). 
Table 2: Difference in feelings between aroused and non-aroused groups

\begin{tabular}{lllllll} 
& & & \multicolumn{3}{c}{ Aroused group } & \multicolumn{2}{c}{ Control group } \\
\cline { 2 - 7 } & $F$ & $p$ & Mean & SD & Mean & $S D$ \\
\hline Affect & & & & & & \\
The pictures made me feel bad & .728 & .395 & 4.89 & 1.79 & 5.13 & 1.75 \\
I was fearful looking at the pictures & 1.54 & .217 & 4.13 & 1.38 & 3.86 & 1.44 \\
The pictures made me feel happy & .998 & .319 & 4.46 & 1.42 & 4.25 & 1.23 \\
I was disgusted by the pictures & .586 & .445 & 4.37 & 1.70 & 4.58 & 1.71 \\
The pictures made me feel good & .428 & .514 & 4.53 & 1.47 & 4.38 & 1.41 \\
The pictures made me feel angry & .973 & .326 & 3.01 & 1.73 & 3.30 & 2.00 \\
The pictures made me feel joyful & .166 & .685 & 4.87 & 1.53 & 4.77 & 1.43 \\
I had pleasant feelings while viewing the pictures & $<.0$ & .996 & 4.40 & 1.71 & 4.41 & 1.41 \\
The pictures made me feel sad & 1.06 & .303 & 5.25 & 1.55 & 4.97 & 1.80 \\
Arousal & & & & & & \\
Sleepy-Awake & 4.70 & .032 & 4.29 & 1.65 & 3.71 & 1.68 \\
Sluggish-Frenzied & 4.40 & .037 & 4.34 & 1.73 & 3.75 & 1.78 \\
Jittery-Dull & 2.18 & .142 & 4.03 & 1.87 & 3.61 & 1.71 \\
Stimulated-Relaxed & 5.77 & .017 & 4.37 & 1.77 & 3.74 & 1.48 \\
Excited-Calm & 4.01 & .047 & 4.49 & 1.80 & 3.94 & 1.64 \\
Aroused-Unaroused & 3.78 & .054 & 4.62 & 1.53 & 4.16 & 1.39 \\
\hline
\end{tabular}

Note. $\mathrm{N}=160$ participants were randomly distributed between the two groups

A one-way ANOVA suggested the severity of personal disclosure was higher in the treatment group $(M=4.41, S D=1.92,95 \% \mathrm{CI}=[4.03,4.80])$ than the control group $(M=3.69$, $\left.S D=1.79,95 \% \mathrm{CI}=[3.26,4.14] ; F(1,158)=5.86, p=.017, \eta^{2}=.036\right)$, providing support for our main hypothesis that the severity of the experience disclosed by aroused participants would be greater than non-aroused participants.

Regression analysis was then used to test whether aroused participants were more likely to disclose information they intended to keep a secret (PROCESS, model 4, Hayes 2013). The results indicated that arousal was a significant predictor of the Secret variable $B=.643, S E$ $=.303, \mathrm{p}=.035$, and that the Secret variable was a significant predictor of severity of disclosure 
$B=.372, S E=.072, \mathrm{p}<.001$. Arousal's effect on disclosure was non-significant after controlling for the Secret variable as a mediator, $B=.478, S E=.279, p=.088$, suggesting the Secret variable mediated the effects of arousal on disclosure. Approximately $18 \%$ of the variance of Severity was accounted for by the predictors $\left(R^{2}=.175\right)$. The indirect coefficient was significant, $B=.239, S E=.118,95 \% C I=[.017, .485]$. These results support the hypothesis that secret information mediates the relationship between arousal and severity, and therefore our theory that arousal increases the likelihood of disclosing information that requires some degree of effort to conceal.

To discount the possibility that aroused participants may have shared more personal information to enhance relationship building, and to ensure there were no baseline differences between the groups, one-way ANOVAs were calculated to compare need to belong and selfpresentation between control and treatment groups. The results suggested no significant difference in self-promotion between groups $\left(M_{\text {treatment }}=3.99, S D_{\text {treatment }}=1.04 ; M_{\text {control }}=4.06\right.$, $\left.\left.S D_{\text {control }}=3.99,95 \% C I=[-.266, .408]\right) F(1,157)=0.18, p=.934, \eta^{2}=.001\right) ;$ and no significant difference in Need to Belong between groups $\left(M_{\text {treatment }}=3.94, S D_{\text {treatment }}=1.21\right.$; $\left.\left.M_{\text {control }}=3.93, S D_{\text {control }}=1.26,95 \% C I=[-.392, .384]\right) F(1,158)<.001, p=.984, \eta^{2}<.001\right)$, thereby casting doubt on the notion that arousal's effect on disclosure might be explained by a need to build a relationship with others.

Taken together, these results find further support for our theory that arousal increases the likelihood of disclosing personal information. The results suggest that arousal increases the likelihood of disclosing information that one would normally take efforts to conceal.

\section{Study 3}


In studies 1 and 2 we found evidence to suggest that arousal increases the intensity (study 1) and severity (study 2) of personal information. In study 3 we test how arousal affects disclosure by asking participants directly if they would be willing to disclose personal information. This contrasts with studies 1 and 2 where we had judges evaluating the degree of personal disclosure. Two further objectives were to separate the arousal from the task by evoking physiological arousal, and to explore how disclosure of thoughts is dependent on how often the thoughts are thought about ("thought frequency") by testing thought frequency as a moderator. Evoking physiological arousal rather than affective or cognitive arousal provides a stronger test of our arousal-increases-disclosure hypothesis by ensuring that disclosure is not influenced by competing thought processes, given we used the story of an impending math test to evoke arousal in study 1 and images in study 2 . The purpose of evaluating thought frequency was to lend support to our theory that self-disclosure of highly personal information when aroused might be a dominant response, since a dominant response is characterized by habitual thoughts (Zajonc \& Sales, 1966), and information that takes some degree of effort to conceal, such as highly personal information, is often thought about (Slepian, et al., 2017) and therefore habitual.

\section{1 Method}

7.1.1. Participants and Design. One hundred and sixty-nine university students (46\% female, average age 19) participated in the study in return for a \$20 gift card. A sensitivity analysis conducted with G*Power (Faul, et al., 2007) suggested that the sample size $N=169$ was sufficient to detect medium-sized effects, $f=0.15$; assuming $\alpha=0.05$ and power $=0.80$. Participants were randomly split into two groups: a control group, and treatment group where arousal was evoked in a between-subjects design. No data were excluded from analyses. 
7.1.2. Procedure. The study was completed in a computer laboratory. Participants were told the purpose of the study was to learn about life experiences. All participants were asked to think back to their high school days and write about an experience when they felt very embarrassed. Since the average age of participants was 19, we expected the experiences would have occurred 1-7 years prior. After participants had finished writing, they were asked to move a slider to indicate how often they had thought about the embarrassing experience since it happened ( 0 times - 100 times). To evoke arousal in the treatment group, after writing about their experience all participants were asked to jog in place for 60 seconds.

Immediately after the jogging task (control: instead of), all participants were asked if they would be willing to disclose (anonymously) their embarrassing experience in a fictitious case study that would be shared with other high school students. The dependent variable used in the analysis was their dichotomous decision to share (Yes/No).

After participants were asked to share their embarrassing experience and indicate how often they had thought about the experience, participants competed the same arousal same scale used in the previous studies.

\section{2 Results and Discussion}

7.2.1. Manipulation check. A one-way ANOVA suggested the treatment group were more aroused after jogging in place $(M=3.37 ; S D=1.00,95 \% \mathrm{CI}=[3.14,3.60]$ than the control $\left.\operatorname{group}(M=2.92, S D=1.46,95 \% \mathrm{CI}=[2.62,3.23]) F(1,167)=5.30, p=.023, \eta^{2}=.03\right)$, suggesting the arousal manipulation was successful.

7.2.2. Willingness to share. The results are reported using unstandardized regression 
coefficients (arousal was included as $0=$ control; $1=$ jogging). In the arousal group, 59\% indicated they would share their story, versus $44 \%$ in the control group. A logistic regression found that arousal predicted willingness to share the embarrassing story $(B=.61, S E=0.31$, Wald $\chi^{2}=3.76, p=.05$ ), lending further support to our theory that aroused people are more willing to publicly disclose highly personal information.

How often participants had thought about their embarrassing experience (thought frequency) was included as a moderator in an equation regressing willingness to disclose on arousal (PROCESS, model 1, Hayes 2013). The results found that the three-variable model with thought frequency included fit better than the constant only model, chi-square $(d f=3)=11.64, p$ $=.009$. Importantly, the interaction between arousal and thought frequency was statistically significant, $b=.038, z(3)=2.20, p=.02895 \% C I[.0041, .0720]$.

These results suggest that the effects of arousal on personal disclosure increases with thoughts that are often thought about, though it is likely that there might be cutoff point where seldom thought-about thoughts would not be disclosed when aroused. Therefore, to identify how many times a response had been thought about before arousal's effect on disclosure became statistically significant, we conducted a Johnson-Neyman significance region analysis (Johnson $\&$ Neyman, 1936). The mean number of times each embarrassing experience was thought about was 24 times $(S D=20.48)$. The analysis found that when the embarrassing experience was thought about less than 24 times, the frequency of thought had no statistically significant moderating effect on arousal. The strength of thought frequency as a moderator increased steadily for embarrassing experiences that had been thought about on average more than 24 times. The results of the Johnson-Neyman analysis are summarized in table 3. 
Table 2: Strength of moderation (number of times thought about) as affecting arousal on personal disclosure

\begin{tabular}{|c|c|c|c|c|c|c|}
\hline \multicolumn{7}{|c|}{ Zones of significance } \\
\hline & \multicolumn{6}{|c|}{ Independent variable $=$ Arousal, Outcome $=$ willingness to share $(\mathrm{Yes} / \mathrm{No})$} \\
\hline $\begin{array}{l}\text { Number of } \\
\text { times thought } \\
\text { about }\end{array}$ & Effect & se & $Z$ & $p$ & $L L C I$ & $U L C I$ \\
\hline 1 & -0.25 & 0.48 & -0.52 & 0.60 & -1.19 & 0.69 \\
\hline 5 & -0.09 & 0.43 & -0.22 & 0.83 & -0.94 & 0.75 \\
\hline 9 & 0.06 & 0.39 & 0.16 & 0.87 & -0.70 & 0.82 \\
\hline 13 & 0.22 & 0.35 & 0.62 & 0.54 & -0.47 & 0.91 \\
\hline 17 & 0.37 & 0.33 & 1.13 & 0.26 & -0.27 & 1.02 \\
\hline 22 & 0.53 & 0.32 & 1.65 & 0.10 & -0.10 & 1.16 \\
\hline 24 & 0.64 & 0.32 & 1.96 & 0.05 & 0.00 & 1.27 \\
\hline 26 & 0.68 & 0.33 & 2.09 & 0.04 & 0.04 & 1.33 \\
\hline 30 & 0.84 & 0.35 & 2.41 & 0.02 & 0.16 & 1.53 \\
\hline 34 & 1.00 & 0.38 & 2.60 & 0.01 & 0.25 & 1.75 \\
\hline 38 & 1.15 & 0.43 & 2.71 & 0.01 & 0.32 & 1.99 \\
\hline 42 & 1.31 & 0.48 & 2.75 & 0.01 & 0.38 & 2.24 \\
\hline 46 & 1.46 & 0.53 & 2.76 & 0.01 & 0.43 & 2.50 \\
\hline 50 & 1.62 & 0.59 & 2.75 & 0.01 & 0.47 & 2.77 \\
\hline 54 & 1.78 & 0.65 & 2.74 & 0.01 & 0.50 & 3.05 \\
\hline 58 & 1.93 & 0.71 & 2.72 & 0.01 & 0.54 & 3.33 \\
\hline 63 & 2.09 & 0.78 & 2.69 & 0.01 & 0.57 & 3.61 \\
\hline 67 & 2.24 & 0.84 & 2.67 & 0.01 & 0.60 & 3.89 \\
\hline 71 & 2.40 & 0.91 & 2.65 & 0.01 & 0.62 & 4.18 \\
\hline 75 & 2.56 & 0.97 & 2.63 & 0.01 & 0.65 & 4.46 \\
\hline 79 & 2.71 & 1.04 & 2.61 & 0.01 & 0.67 & 4.75 \\
\hline 83 & 2.87 & 1.11 & 2.59 & 0.01 & 0.70 & 5.04 \\
\hline
\end{tabular}

$N=163$ respondents

Taken together, these results lend support to our theory that disclosing personal information might be a dominant response that is activated by arousal. Arousal increases the disclosure of often thought about personal information. A potential limitation of this study was that there was a longer break between writing the story and making the decision in the treatment group, which may have resulted in a difference in emotional distance. 


\section{General Discussion}

People take efforts to moderate their disclosure of personal information. Yet although the strategic management of self-disclosure appears to be a part of life, little is known about why people sometimes self-disclose more personal information than they might otherwise would have. In this research, we examined how arousal affects self-disclosure. In three studies we found that arousal increases: the intensity of personal information disclosed (study 1), the severity of personal information disclosed (study 2), and the likelihood of sharing embarrassing experiences (study 3). We demonstrated how both affective and physiological arousal affect selfdisclosure, and found that arousal's impact on self-disclosure depended on how often the information was thought about, with often-thought-about thoughts being disclosed but not seldom thought-about-thoughts.

There are several important implications to our findings. Most importantly, our findings suggest that arousal might increase tendencies to disclose potentially revealing information during times when we might benefit from concealment. Of course, revealing something personal about oneself even in the wrong moment might be perceived as positive. But it might just as well be perceived as negative. What we say is affected by context and saying the wrong thing in the wrong moment may create awkwardness, be offensive, damage trust, or harm perceptions towards our character. The times when we ought to be careful with what we say are often arousing - job interviews, media engagements, important work meetings, or romantic encounters. The news is full of examples of well-known celebrities and businesspeople who have said something regretful, and their experiences remind us not only how common potentially awkward self-disclosures seem to be, but also how damaging a slip of the tongue can be on reputations. 
So how can we better control what we say when aroused? Could simply knowing that arousal might loosen our tongues be enough to retain control? At first blush this might seem like a reasonable assumption, though the research in this area suggests several complications. Notably, engaging self-awareness has been found to increase rather than decrease self-disclosure (Forehand \& Deshpand, 2001; Joinson, 2001). Self-awareness is also thought to contribute to social facilitation effects (Baron, 1986; Rajecki, Ickes, Corcoran, \& Lenerz, 1977), and hence a dominant response, which according to our theory might further weaken, rather than strengthen, efforts to control self-disclosure. Interestingly, research has found that reduced public selfawareness decreases spontaneous self-disclosure (Joinson, 2001), suggesting that perhaps decreasing public self-awareness might increase the ability to conceal certain information in arousing situations, though this proposition as far as we know has never been tested. In short, more research is required to define the boundary conditions of our effect. A logical path forward seems to be focusing on the mechanisms that helps people to 'keep their guard up' and better control what they say. Though as every interrogator will tell you, there are obvious limits when it comes to decoupling the relationship between stress and disclosure.

Our studies focused on the disclosure of personal information. We did not test the possibility that other types of often-thought-about information might also be more likely disclosed when aroused. One might just as much often think about important information that is not necessarily highly personal, such as an upcoming holiday or event. Does arousal also increase the disclosure of important information in general? Given that personal information is probably perceived as being important, it seems that it might. Future research might examine which types of information is, and is not, affected by arousal. A deeper understanding of how different types of information are affected by arousal would also be useful. For example, it seems 
possible that an inverted U-shaped curve might exist, such that relatively insignificant information is seldom thought about and therefore seldom disclosed, and major secrets are too damaging to disclose. We did not test the boundaries of our effect.

A limitation of our research is that all three study designs are in the context of inviting disclosure. To adhere to ethics committee recommendations, our designs invited participants to provide information anonymously. Moreover, participants were asked to disclose information, rather than spontaneously disclosing information without being prompted. A more robust test of the arousal-disclosure relationship might test whether aroused respondents are more likely to disclose information spontaneously, and in a context where their identity might be known.

Theoretically, our findings make progress towards understanding when and why people disclose information. Prior research has examined the effects of concealment on relationship satisfaction and well-being, (Slepian, et al., 2017), how holding information affects perceptual judgements (Slepian, et al., 2015), and the interpersonal aspects of sharing secrets (Slepian \& Kirby, 2018), though the question of when and why arousal increases tendencies to disclose concealed information has remained poorly understood. In this research we put together two prior theories: dominant responses are more likely under arousal, and secrets lead to rumination which might make them a dominant response, to produce our effects. This is an advancement on the theoretical level coupled with the practical contribution of showing that arousal leads to disclosing highly personal information. 


\section{References}

Altman, I., \& Taylor, D. A. (1973). Social penetration: The development of interpersonal relationships. New York: Holt: Rinehart \& Winston.

Baron, R. S. (1986). Distraction-Conflict Theory: Progress and Problems. In L. Berkowitz (Ed.), Advances in Experimental Social Psychology (Vol. 19, pp. 1-40): Academic Press.

Baumeister, R. F., \& Hutton, D. G. (1987). Self-Presentation Theory: Self-Construction and Audience Pleasing. In B. Mullen \& G. R. Goethals (Eds.), Theories of Group Behavior (pp. 71-87). New York, NY: Springer New York.

Bell, D. E. (1982). Regret in Decision Making under Uncertainty. Operations Research, 30(5), 961-981.

Ben-Zeev, T., Fein, S., \& Inzlicht, M. (2005). Arousal and stereotype threat. Journal of Experimental Social Psychology, 41(2), 174-181.

Bond, C. F., \& Titus, L. J. (1983). Social facilitation: a meta-analysis of 241 studies. Psychological Bulletin, 94(2), 265-292.

Buhrmester, M., Kwang, T., \& Gosling, S. D. (2011). Amazon's Mechanical Turk: A New Source of Inexpensive, Yet High-Quality, Data? Perspectives on Psychological Science, $6(1), 3-5$. 
Cacioppo, J. T., Hawkley, L. C., Norman, G. J., \& Berntson, G. G. (2011). Social isolation. Annals of the New York Academy of Sciences, 1231(1), 17-22.

Cameron, J. J. (2009). When self-disclosure goes awry: Negative consequences of revealing personal failures for lower self-esteem individuals. Journal of Experimental Social Psychology, 45(1), 217.

Cline, R. J. W. (1989). The Politics of Intimacy: Costs and Benefits Determining Disclosure Intimacy in Male-Female Dyads. Journal of Social and Personal Relationships, 6(1), 520. doi: $10.1177 / 026540758900600101$

Conrey, F. R., Sherman, J. W., Gawronski, B., Hugenberg, K., \& Groom, C. J. (2005). Separating Multiple Processes in Implicit Social Cognition: The Quad Model of Implicit Task Performance. Journal of Personality and Social Psychology, 89(4), 469-487.

Dindia, K. (2001). Self-Disclosure Research: Knowledge through Meta-Analysis. In M. Allen, R. W. Preiss, B. M. Gayle \& N. Burrell (Eds.), Interpersonal Communication Research: Advances Through Meta-analysis (1 ed.): Routledge

Dindia, K., Fitzpatrick, M. A., \& Kenny, D. A. (1997). Self-Disclosure in Spouse and Stranger Interaction: A Social Relations Analysis. Human Communication Research, 23(3), 388412. doi: 10.1111/j.1468-2958.1997.tb00402.x

Faul, F., Erdfelder, E., Lang, A.-G., \& Buchner, A. (2007). G*Power 3: A flexible statistical power analysis program for the social, behavioral, and biomedical sciences. [journal article]. Behavior Research Methods, 39(2), 175-191. doi: 10.3758/bf03193146 
Forehand, M. R., \& Deshpand, R. (2001). What We See Makes Us Who We Are: Priming Ethnic Self-Awareness and Advertising Response. Journal of Marketing Research, 38(3), 336348.

Gold, D. B., \& Wegner, D. M. (1995). Origins of Ruminative Thought: Trauma, Incompleteness, Nondisclosure, and Suppression. Journal of Applied Social Psychology, 25(14), 12451261. doi: 10.1111/j.1559-1816.1995.tb02617.x

Guerin, B. (2009). Social facilitation. Cambridge: UK: Cambridge University Press.

Hewitt, P. L., Flett, G. L., Sherry, S. B., Habke, M., Parkin, M., Lam, R. W., . . Stein, M. B. (2003). The interpersonal expression of perfection: Perfectionistic self-presentation and psychological distress. Journal of Personality and Social Psychology, 84(6), 1303-1325. doi: 10.1037/0022-3514.84.6.1303

Hull, C. (1943). Principles of Behavior.

Johnson, P. O., \& Neyman, J. (1936). Tests of certain linear hypothesis and their application to some educational problems. Statistical Research Memoirs(1), 57-93.

Joinson, A. N. (2001). Self-disclosure in computer-mediated communication: The role of selfawareness and visual anonymity. European Journal of Social Psychology, 31(2), 177192. doi: doi:10.1002/ejsp.36

Lambert, A. J., Payne, B. K., Jacoby, L. L., Shaffer, L. M., Chasteen, A. L., \& Khan, S. R. (2003). Stereotypes as Dominant Responses: On the "Social Facilitation" of Prejudice in 
Anticipated Public Contexts. Journal of Personality and Social Psychology, 84(2), 277295.

Lane, J. D., \& Wegner, D. M. (1995). The cognitive consequences of secrecy. Journal of Personality and Social Psychology, 69(2), 237-253. doi: 10.1037/0022-3514.69.2.237

Lang, P. J., Bradley, M. M., \& Cuthbert, B. N. (1997). International Affective Picture System (IAPS): Technical Manual and Affective Ratings: NIMH Center for the Study of Emotion and Attention.

Leary, M. R. (2010). Social Anxiety as an Early Warning System: A Refinement and Extension of the Self-Presentation Theory of Social Anxiety. In S. G. Hofmann \& P. M. DiBartolo (Eds.), Social Anxiety (pp. 472-483). London: Elsevier.

Leary, M. R., Kelly, K. M., Cottrell, C. A., \& Schreindorfer, L. S. (2013). Construct validity of the need to belong scale: mapping the nomological network. Journal of Personality Assessment, 95(6), 610-624. doi: 10.1080/00223891.2013.819511

Lennox, R. D., \& Wolfe, R. N. (1984). Revision of the self-monitoring scale. Journal of Personality and Social Psychology, 46(6), 1349-1364.

Noseworthy, T. J., Muro, F. D., \& Murray, K. B. (2014). The Role of Arousal in CongruityBased Product Evaluation. Journal of Consumer Research, 41(4), 1108 - 1126.

Okken, V., Rompay, T. v., \& Pruyn, A. (2013). Room to Move: On Spatial Constraints and SelfDisclosure During Intimate Conversations. Environment and Behavior, 45(6), 737-760. 
Omarzu, J. (2000). A Disclosure Decision Model: Determining How and When Individuals Will Self-Disclose. Personality and Social Psychology Review, 4(2), 174-185. doi: 10.1207/s15327957pspr0402_05

Paolacci, G., Chandler, J., \& Ipeirotis, P. G. (2010). Running experiments on Amazon Mechanical Turk. Judgment and Decision Making, 5(5), 411-419.

Pennebaker, J. W. (1995). Emotion, disclosure, \& health. Washington, DC, US: American Psychological Association.

Place, S. S., Todd, P. M., Penke, L., \& Asendorpf, J. B. (2009). The Ability to Judge the Romantic Interest of Others. Psychological Science, 20(1), 22-26. doi: 10.1111/j.14679280.2008.02248.x

Rajecki, D. W., Ickes, W., Corcoran, C., \& Lenerz, K. (1977). Social Facilitation of Human Performance: Mere Presence Effects. The Journal of Social Psychology, 102(2), 297310.

Rubin, Z. (1975). Disclosing oneself to a stranger: Reciprocity and its limits. Journal of Experimental Social Psychology, 11(3), 233.

Ruppel, E. K., Gross, C., Stoll, A., Peck, B. S., Allen, M., \& Kim, S.-Y. (2016). Reflecting on Connecting: Meta-Analysis of Differences between Computer-Mediated and Face-toFace Self-Disclosure. Journal of Computer-Mediated Communication, 22(1), 18-34. doi: $10.1111 /$ jcc4.12179 
Sato, T. (2005). The Eysenck Personality Questionnaire Brief Version: Factor Structure and Reliability. The Journal of Psychology, 139(6), 545-552.

Schimmack, U., \& Grob, A. (2000). Dimensional Models of Core Affect: a Quantitative Comparison by Means of Structural Equation Modeling. European Journal of Personality, 14(4), 325-345.

Slepian, M. L., Camp, N. P., \& Masicampo, E. J. (2015). Exploring the secrecy burden: Secrets, preoccupation, and perceptual judgments. Journal of Experimental Psychology: General,, 144, 31-42.

Slepian, M. L., Chun, J. S., \& Mason, M. F. (2017). The experience of secrecy. Journal of Personality and Social Psychology, 113(1), 1-33. doi: 10.1037/pspa0000085

Slepian, M. L., \& Kirby, J. N. (2018). To Whom Do We Confide Our Secrets? Personality and Social Psychology Bulletin, 44(7), 1008-1023. doi: 10.1177/0146167218756032

Spinella, M. (2007). Normative Data and A Short Form of the Barratt Impulsiveness Scale International Journal of Neuroscience, 117(3), 359-368.

Sprecher, S., Treger, S., Wondra, J. D., Hilaire, N., \& Wallpe, K. (2013). Taking turns: Reciprocal self-disclosure promotes liking in initial interactions. Journal of Experimental Social Psychology, 46, 860-866.

Tolstedt, B. E., \& Stokes, J. P. (1984). Self-disclosure, Intimacy, and the Depenetration Process. Journal of Personality and Social Psychology, 46(1), 84-90. 
Wegner, D. M., Schneider, D. J., Carter, S. R., \& White, T. L. (1987). Paradoxical effects of thought suppression. Journal of Personality and Social Psychology, 53(1), 5-13. doi: $10.1037 / 0022-3514.53 .1 .5$

Yu, R.-f., \& Wu, X. (2015). Working alone or in the presence of others: exploring social facilitation in baggage X-ray security screening tasks. Ergonomics, 58(6), 857-865. doi: $10.1080 / 00140139.2014 .993429$

Zajonc, R. B. (1965). Social facilitation. Science, 149(3681), 269-274.

Zajonc, R. B., \& Sales, S. M. (1966). Social facilitation of dominant and subordinate responses. Journal of Experimental Social Psychology, 2(2), 160-168. 